\title{
Unambiguous identification of esters as oligomers in secondary organic aerosol formed from cyclohexene and cyclohexene $/ \alpha$-pinene ozonolysis
}

\author{
L. Müller, M.-C. Reinnig, J. Warnke, and Th. Hoffmann \\ Johannes Gutenberg-Universität, Institut für anorganische Chemie und analytische Chemie, Duesbergweg 10-14, 55128 \\ Mainz, Germany
}

Received: 2 August 2007 - Published in Atmos. Chem. Phys. Discuss.: 26 September 2007

Revised: 10 January 2008 - Accepted: 13 February 2008 - Published: 11 March 2008

\begin{abstract}
The build-up of oligomeric compounds during secondary organic aerosol (SOA) formation is subject of atmospheric research since several years. New particle formation and especially the SOA mass yield might be influenced significantly by oligomer formation. However, the chemical nature of observed oligomers and their formation pathways are still unclear. In this paper, the structural characterization of certain dimeric compounds (esters) formed during the ozonolysis of cyclohexene and cyclohexene/ $\alpha$-pinene mixtures are presented. The identification is based on the comparison of the mass spectra and the retention times (LC) of the oligomeric products with synthesized reference compounds. Cyclohexene is used here as a model compound for terpenes as globally most important SOA precursors, since it possesses a simpler structure than the biogenic alkenes and therefore offers the possibility to get access to reference compounds for certain of its oxidation products. In addition to cyclohexene, the formation of esters could also be observed in experiments with $\alpha$-pinene as reactant.
\end{abstract}

\section{Introduction}

Aerosols attract attention in atmospheric research due to their effects on climate and human health. Secondary aerosols that are aerosols formed in the gas phase by chemical reactions of volatile precursors - typically have diameters between a few and some hundred nanometres. Therefore, the atmospheric lifetime of most of these secondary particles is relatively high (Finlayson-Pitts and Pitts, 2000). In addition, they have the ability to be inhaled deep into the human lungs (Hinds, 1999).

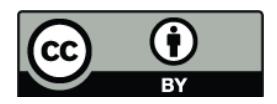

Correspondence to: Th. Hoffmann (hoffmant@uni-mainz.de)
Monoterpenes are believed to be the major contributors to secondary organic aerosol (SOA) emitted by biogenic sources (Lack et al., 2004; Tsigaridis and Kanakidou, 2003), although recently also isoprene received attention in respect to its potential to form SOA (Claeys et al., 2004). The special scientific interest about the atmospheric chemistry of these natural alkenes is mainly due to the tremendous amounts emitted globally from tropical, temperate or boreal forests. However, also indoor air can contain considerable amounts of terpenes, emitted from furniture, solvents or air fresheners (Baumann et al., 1999; Hodgson et al., 2002; Sarwar et al., 2004). The gas phase reactions of these alkenes with reactive atmospheric species (ozone, $\mathrm{OH}$-radicals, $\mathrm{NO}_{3}$-radicals) lead to the formation of products with lower vapour pressures. These low volatile oxidation products then generate SOA, either by new particle formation (homogeneous nucleation) or by condensation on pre-existing particles (Bowman et al., 1997; Finlayson-Pitts and Pitts, 2000; Hoffmann et al., 1997; Holmes, 2007; Odum et al., 1996; Seinfeld and Pandis, 1998).

The molecular level characterization of SOA observed in the laboratory or in the ambient atmosphere has proven to be a difficult task. During the last years, several atmospheric simulation chamber experiments have been conducted, most of them focussed on the estimation of aerosol mass yields from different VOCs. Several groups also concentrated on the chemical characterization of SOA but a significant part remains unclear. The large number of products even from a single precursor VOC and the wide range of polarities of the products make the analysis on a molecular level difficult. Several classes of products (i.e. alcohols, carbonyls, acids, peroxides, nitrates) have been identified and it could be shown in numerous laboratory and field studies that various organic acids (monoacids, diacids, hydroxy acids etc.) are major contributors to the particle phase from monoterpene precursors (Alves et al., 1999; Anttila et al., 2005; Glasius et al., 2000; Hoffmann et al., 1998; Kavouras et al.,

Published by Copernicus Publications on behalf of the European Geosciences Union. 
1999; Koch et al., 2000; Larsen et al., 2001; Warnke et al., 2006; Yu et al., 1999). However, recent results showed evidence that not only the introduction of oxygen-containing functional groups into the precursor molecule is responsible for the lower vapour pressure of the oxidation products, but that also higher molecular weight products (oligomers) can be formed (Barsanti and Pankow, 2006; Gao et al., 2004; Kalberer et al., 2004; Tolocka et al., 2004).

For cycloalkene (terpene) SOA experimental studies propose various possible oligomer products, such as peroxyhemiacetales (Docherty et al., 2005), alkoxyhydroperoxides (Tobias and Ziemann, 2000), dicarboxylic acid dimers (Hoffmann et al., 1998), diacyl peroxides (Ziemann, 2002), esters and carboxylic acid anhydrides (Hamilton et al., 2006), hemiacetals and acetals (Iinuma et al., 2004). This broad list of potential candidates indicates the current understanding of the molecular identities of the higher molecular weight products. The most important consequence of the existing lack of knowledge about the chemical structures of the oligomers is the inability to incorporate oligomer formation into atmospheric modelling, since their formation mechanism remains unknown. Even the use of different mass spectrometric techniques, such as the combination of selective fragmentation using ion trap MS and the determination of the elemental composition by high resolution time of flight-MS still leaves room for speculation (Hamilton et al., 2006).

The aim of this work was the unambiguous identification of the molecular identity of certain dimer compounds in SOA. For this purpose a complementary combination of on-line atmospheric pressure chemical ionization mass spectrometry (APCI-MS ${ }^{n}$ ) and off-line liquid chromatography electrospray ionization mass spectrometry was used

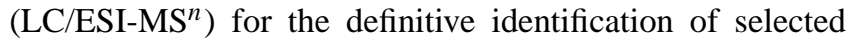
oligomer products observed from cyclohexene ozonolysis. The ozonolysis of cyclohexene has been chosen as a simplified system to investigate the composition and formation of dimeric products generated during ozonolysis. Even though cyclohexene has a lower relevance for atmospheric processes, it is - as a cyclic alkene - an appropriate surrogate for monoterpenes and, more importantly, allows access to specific reference compounds by organic synthesis. Therefore, the identification of certain dimeric products could be carried out by comparing retention time and $\mathrm{MS}^{n}$-spectra of synthesized reference compounds to the data received from smog-chamber experiments. In the last step of the investigations presented here, results of cross experiments in respect to dimer formation are discussed, in which cyclohexene is introduced into an ongoing $\alpha$-pinene-ozone chamber experiment.

\section{Experimental section}

\subsection{Materials}

Delta-valerolactone (\#162710500; 99\%), epsiloncaprolactone (\#162710500; 99\%), gamma-butyrolactone (\#108130250; 99+\%), succinic acid (\#219550250; 99+\%) and glutaric acid (\#119960250; 99\%) were obtained from Acros Organics, adipic acid (\#09582; $\geq 99,5 \%)$, pinic acid (\#S762792; $\geq 99 \%)$ and cyclohexene (\#240990; $\geq 99 \%)$ from Sigma-Aldrich, sulphuric acid (\#84720; 95-97\%), HPLC grade solvents (methanol, acetone and acetonitrile) from Carl Roth and $\alpha$-pinene (\#80606; $\geq 99 \%$ ) from Fluka. Gases (nitrogen 5.0, synthetic air) were obtained from Westfalen.

\subsection{Chamber experiments}

The ozonolysis of cyclohexene and the monoterpene $\alpha$ pinene was carried out under dark and dry conditions $(<1 \%$ r.h.) without seed particles in a cylindrical $100 \mathrm{~L}$ reaction chamber made of glass. No $\mathrm{OH}$ scavengers were used. The chamber was constantly flushed with a hydrocarbon containing nitrogen flow $(0.5 \mathrm{~L} / \mathrm{min})$, dry synthetic air $(2.1 \mathrm{~L} / \mathrm{min})$ and an ozone-containing air stream $(2.6 \mathrm{~L} / \mathrm{min})$. Therefore, the reaction chamber can be considered as a continuous stirred-tank reactor (CSTR) with a mean residence time of the reactants of about 19 min. A total concentration of $1 \mathrm{ppm}$ ozone was adjusted by UV irradiation of the ozone-containing air supply using the ozone generator of an ozone analyzer (Dasibi Environmental Corp, Model 1008-RS, Glendale California). The same instrument was used for monitoring the ozone concentration during the experiments. The VOCs were added into the chamber by using temperature-controlled, nitrogen flushed test gas sources, which were based on an open tube diffusion technique. The resulting hydrocarbon concentration in the chamber was about $200 \mathrm{ppb}$ for monoterpene experiments and about $1000 \mathrm{ppb}$ for cyclohexene experiments. The particle number concentration in the chamber was measured using a CPC (condensation particle counter, Porta Count Plus, TSI Corp., USA). To determine the chemical composition of secondary organic aerosol, two complementary methods were applied: On-line analysis via an ion-trap mass spectrometer with an atmospheric pressure chemical ionization source (APCI-IT/MS ${ }^{n}$ ) as well as an off-line investigation using liquid chromatography technique coupled with electrospray ionization source ion-trap mass spectrometer (HPLCESI-IT/MS ${ }^{n}$ ).

\subsection{Sample collection and sample preparation}

Particulate ozonolysis products were collected on $70 \mathrm{~mm}$ PTFE coated quartz fibre filters (PALLFLEX T60A20, Pall Life Science, USA) with a flow of $4.5 \mathrm{~L} / \mathrm{min}$ and a sampling time of $6 \mathrm{~h}$. The total sample volume added up to 
$1.6 \mathrm{~m}^{3}$. The collected filter samples were stored at $5^{\circ} \mathrm{C}$. For HPLC ESI-IT/MS investigations half of the filter sample was extracted two times for about 30 min with $2 \mathrm{~mL}$ extraction agent (methanol/water 1:10 v/v) by sonification. After filtration (Sartorius Minisart SRP4, PTFE-membrane $0.45 \mu \mathrm{m}$ ) the unified extracts were concentrated under a gentle steam of nitrogen and heating $\left(60^{\circ} \mathrm{C}\right)$ to a total volume of $0.2 \mathrm{~mL}$.

\subsection{HPLC-ESI-IT/MS Measurements (LC/MS ${ }^{n}$ )}

The obtained extracts were investigated by HPLC-ESIIT/MS $^{n}$ measurements using a HCT-Plus ion trap mass spectrometer (Bruker-Daltonics GmbH, Bremen, Germany) equipped with a HPLC-System (Agilent 1100 series, auto sampler, gradient pump and degasser, Agilent Technologies $\mathrm{GmbH}$, Germany) and a Pursuit XRs 3 C8 $150 \mathrm{~mm} \times 2.0 \mathrm{~mm}$ column with $3 \mu \mathrm{m}$ particle size (Varian, Germany).

The eluents were HPLC grade water (Milli-Q water system, Millipore, Bedford, USA) with $0.1 \%$ formic acid and $2 \%$ acetonitrile (eluent $\mathrm{A}$ ) and acetonitrile with $2 \%$ water (eluent B). The gradient of the mobile phase, with a flow of $0.2 \mathrm{~mL} / \mathrm{min}$, was chosen as follows: Starting with $0 \% \mathrm{~B}$, gradient to $100 \% \mathrm{~B}$ in $30 \mathrm{~min}$, isocratic for $5 \mathrm{~min}$ and gradient to $0 \% \mathrm{~B}$ in $5 \mathrm{~min}$. The column was equilibrated at $0 \%$ $\mathrm{B}$ for $20 \mathrm{~min}$. The LC System was directly connected to the electrospray ion source with the following setup: nebulizer pressure $2200 \mathrm{mbar}$, dry gas flow $10 \mathrm{~L} / \mathrm{min}$, dry gas temperature $365^{\circ} \mathrm{C}$, spray voltage $4500 \mathrm{~V}$. The ion optic of the mass spectrometer, operated in the negative ion mode, was optimized for adipic acid (negative ion mode $\mathrm{m} / \mathrm{z} 145$ ).

\subsection{On-line APCI/MS}

When the investigation of the particle phase is aiming on the chemical characterization of particle phase products, it is favourable to apply a suitable on-line technique in addition to off-line filter investigations. The on-line technique used here allows a direct introduction of the reaction mixture into the ion source. Possible analytical artefacts, such as incomplete analyte extraction or reactions during sampling or extraction can be avoided. Furthermore, on-line measurements provide temporally resolved insights in the formation of secondary organic aerosol (Hoffmann et al., 1998). On the other hand the on-line technique provides no separation of the analytes before ionisation and detection. Therefore, the results can be affected by isobaric interferences and an unambiguous identification of single compounds is very difficult.

On-line-APCI/MS and -MS/MS analyses were performed using a LCQ ion trap mass spectrometer (Finnigan MAT, USA) with a modified atmospheric pressure chemical ionization source (Hoffmann et al., 1998) in the negative ion mode (Finnigan MAT, USA). The parameters were set to: $2 \mu \mathrm{A}$ discharge current, $350^{\circ} \mathrm{C}$ vaporizer temperature, $200^{\circ} \mathrm{C}$ capillary temperature, $-7.8 \mathrm{~V}$ capillary voltage, $16.4 \mathrm{~V}$ lens voltage. The sheath gas flow rate was set to 5 units (arbitrary

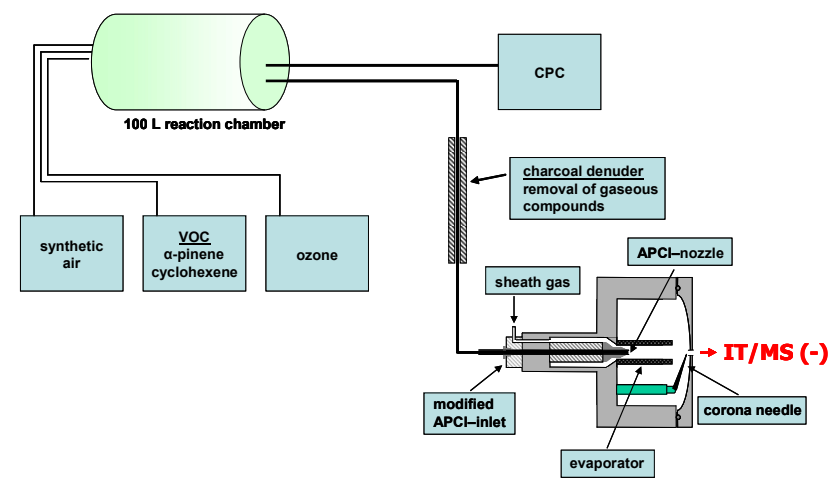

Fig. 1. Sketch of the modified atmospheric pressure chemical ionization source (APCI) and the analytical setup used for on-line measurements.

units defined by the instrument software). The APCI/MS/MS experiments were recorded at different collision energies and helium was used as the collision gas. To separate the gas phase from the generated particle phase a charcoal-filled diffusion denuder was connected between reaction chamber and ion source (Fig. 1).

\subsection{Synthesis}

The synthesis of ester standards was carried out in a $250 \mathrm{~mL}$ reaction flask. A solution of $0.01 \mathrm{~mol}$ carboxylic acid and $0.01 \mathrm{~mol}$ lactone in $30 \mathrm{~mL}$ acetone was acidified with two drops of concentrated sulphuric acid and refluxed for $2 \mathrm{~h}$. Without any further purification the reaction solution was diluted by a factor of 1:1000 with a methanol/water - mixture $(1: 10 \mathrm{v} / \mathrm{v})$. The diluted solution was characterized by HPLCESI-IT/MS ${ }^{n}$.

\section{Results and discussions}

\subsection{Cyclohexene ozonolysis}

The cyclohexene-ozone system has been intensively studied earlier as a simplified system for the reactions of cyclic monoterpenes with endocyclic double bonds and ozone (Gao et al., 2004; Kalberer et al., 2000). Several monomeric products in the mass range between $\mathrm{m} / \mathrm{z} 100$ and $\mathrm{m} / \mathrm{z} 210$ were identified and reasonable suggestions about the underlying reaction mechanisms have been published (Ziemann, 2003). Figure $2 \mathrm{a}$ shows the on-line mass spectra of cyclohexeneozone reaction products in the particle phase recorded in the negative ion mode as described above. The use of APCI(-) will usually result in the formation of $[\mathrm{M}-\mathrm{H}]^{-}$quasimolecular ions, especially for acidic compounds such as organic acids. The $\mathrm{m} / \mathrm{z}$ ratios up to $\mathrm{m} / \mathrm{z} 145$ shown in Fig. 2a can mostly be explained by simple reaction products, e.g. $m / z 145$ (adipic acid), $m / z, 131$ (glutaric acid) and $\mathrm{m} / \mathrm{z}, 129$ (6-oxohexanoic acid). However, it is obvious from 

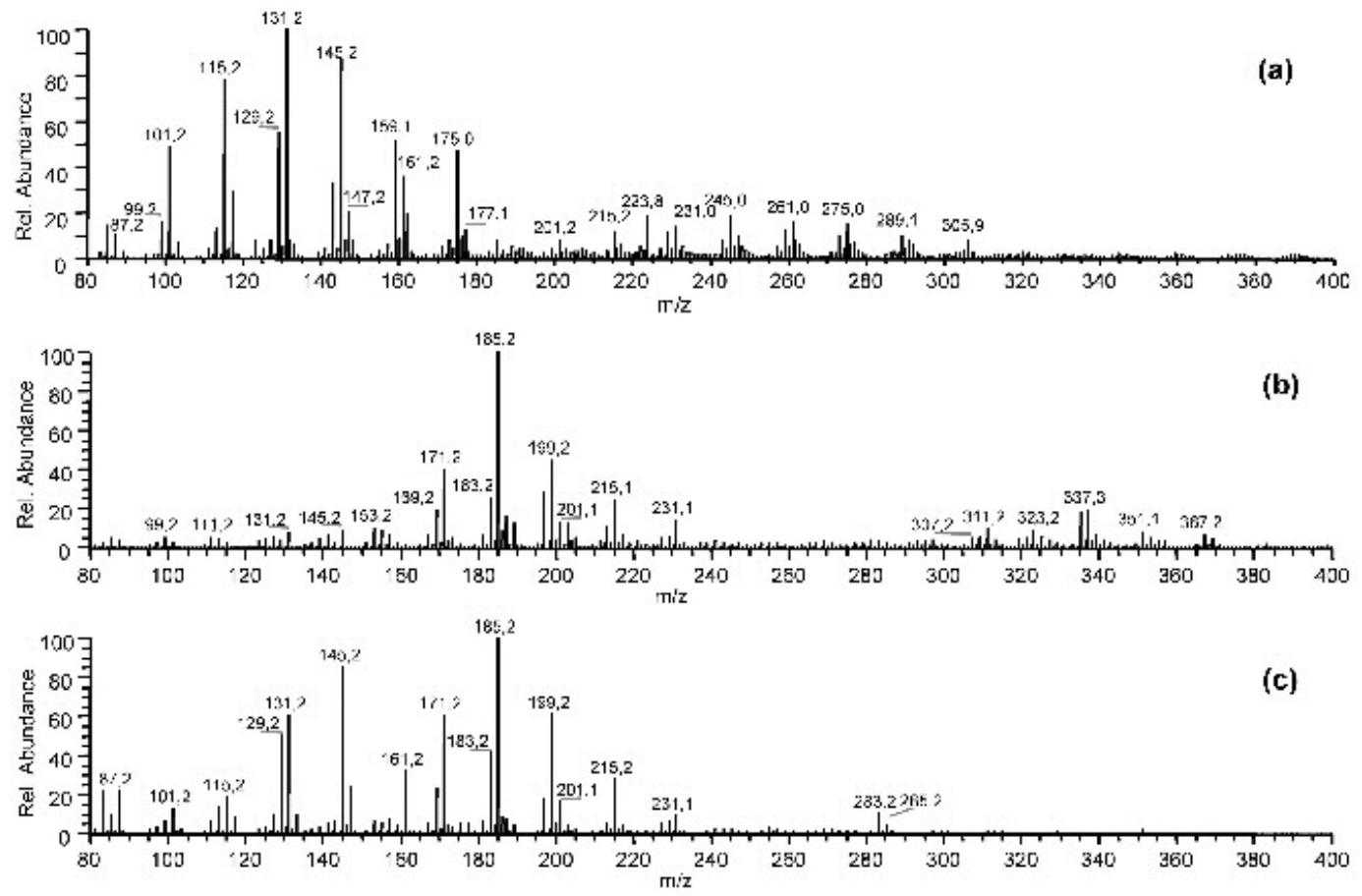

Fig. 2. On-Line mass spectra of cyclohexene/ $\mathrm{O}_{3}$ reaction (a), $\alpha$-pinene $/ \mathrm{O}_{3}$ reaction (b) and cross-experiment of $\alpha$-pinene and cyclohexene with $\mathrm{O}_{3}$ (c).

Fig. 2a that also higher molecular weight compounds are formed in the reaction of cyclohexene with ozone $(\mathrm{m} / \mathrm{z}$ between about 200 and 320). As mentioned above, different explanations for potential dimeric structures have been suggested in similar reaction systems in the past (Docherty et al., 2005; Hoffmann et al., 1998; Iinuma et al., 2004; Tobias and Ziemann, 2000; Ziemann, 2002). One of the most recent suggestions comes from Hamilton and co-workers, who suggested the formation of esters or carboxylic acid anhydrides as high molecular weight products (Hamilton et al., 2006).

To verify if esters are formed from cyclohexene ozonolysis, the LC/MS ${ }^{n}$ measurements of filter samples from chamber experiments were compared with LC/MS ${ }^{n}$ measurements of certain synthesized reference esters. Table 1 shows an overview of all synthesized ester compounds. $\mathrm{MS}^{2}$ - and $\mathrm{MS}^{3}$-spectra of the reference esters are shown in Fig. 3. The comparison is shown in Fig. 4, where the base-peak chromatogram of a filter sample from the cyclohexene ozonolysis (black line, Fig. 4a) and the corresponding extracted ion chromatogram of $\mathrm{m} / \mathrm{z} 245$ from the same sample (red line, Fig. 4a) are directly compared with the extracted ion chromatogram of $\mathrm{m} / \mathrm{z} 245$ from two synthesized standards, hexanedioic acid mono-(4-carboxy-butyl)ester (red, Fig. 4b) and pentanedioic acid mono-(5-carboxy-pentyl)ester (green, Fig. 4b). The third (not labelled) peak at $17.0 \mathrm{~min}$ (green line, Fig. 4b) is a by-product of the ester synthesis, the condensation product of two hydroxyhexanoic acid molecules (6-hydroxyhexanoic acid 5-carboxy-pentylester), which derive from hydrolysis of $\varepsilon$-caprolactone. This product could also be found in the chamber samples, however, just in very low concentrations. In the $m / z, 245$ extracted ion chromatogram of the filter sample (red line, Fig. 4a) some additional peaks can be seen but they have not been identified yet. Overall, six esters could be unambiguously identified in the cyclohexene-SOA by the comparison of their retention times and fragmentation patterns with synthesized reference compounds. The other esters observed in SOA from cyclohexene ozonolysis were pentanedioic acid mono(4-carboxypropyl)ester $(\mathrm{m} / \mathrm{z} 218)$, pentanedioic acid mono(4-carboxybutyl)ester $(\mathrm{m} / \mathrm{z} 232)$, hexanedioic acid mono-(3-carboxypropyl)ester $(\mathrm{m} / \mathrm{z}, 232)$ and in traces hexanedioic acid mono-(5-carboxy-pentyl)ester $(\mathrm{m} / \mathrm{z}$ 259). Other synthesized esters that could in principle be formed in the cyclohexene-ozone system, such as butanedioic acid mono(5-carboxypentyl)ester $(\mathrm{m} / \mathrm{z}, 232)$ and 2oxopentanedioic acid mono-(4-carboxybutyl)ester $(\mathrm{m} / \mathrm{z} 245)$, were not found. The synthesized esters are all characterized by an additional carboxyl group at the alcohol-moiety, see Fig. 3. The fragmentation patterns are very similar for each compound. The first fragmentation occurs at the ester group. The quasi-molecular ion of the dicarboxylic acid is the most abundant fragment ion. However, also the hydroxyl component of the ester is observable in the MS/MS spectra in different intensities. The intensity seems to be dependent on the molecular weight of the hydroxyl component or the ratio of molecular weights of hydroxyl and dicarboxylic acid 

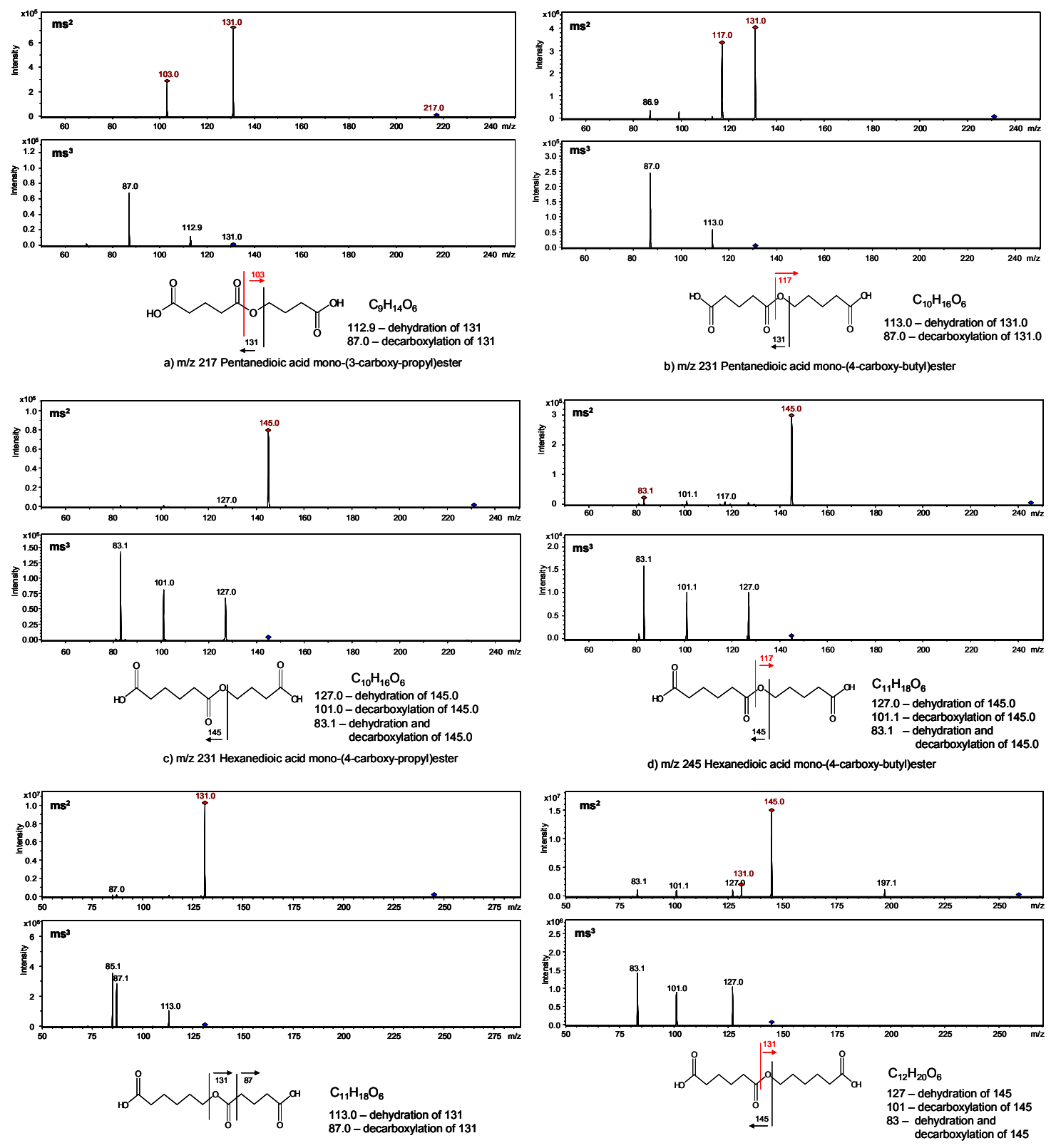

Fig. 3. Structures and fragmentation patterns of synthesized ester compounds.

component in the ester molecules. Furthermore, always visible in the MS/MS-spectra are low intensities of fragments from losses of water, carbon dioxide and combined losses of water and carbon dioxide of the dicarboxylic acid, which is typical for dicarboxylic acids of different chain length (Grossert et al., 2005). The $\mathrm{MS}^{3}$-spectrum of the $\mathrm{m} / \mathrm{z}, 131$ fragment ion (Fig. 3d), show a loss of $46 \mathrm{Da}(\mathrm{m} / \mathrm{z}$ 85), which likely corresponds to a loss of formic acid. The loss of $46 \mathrm{Da}$ is not expected from the diacid precursor ion but from the hydroxycarboxylic acid, which in this case has the same mass.

\section{$3.2 \alpha$-Pinene/cyclohexene cross experiment}

Based on the knowledge about the ester formation in the cyclohexene/ozone system, similar experiments were carried out with the more relevant $\alpha$-pinene/ozone system. Unfortunately, the relative complex structure of the $\alpha$-pineneskeleton makes the access to appropriate reference compounds by organic synthesis extremely difficult. Therefore, an experiment in which cyclohexene was added to an ongoing $\alpha$-pinene ozonolysis experiment was conducted. Figure $2 b$ shows the on-line APCI-MS spectra of SOA 
Table 1. Synthesized ester structures and retention times in LC-MS/MS chromatograms.

\begin{tabular}{|c|c|c|c|c|c|c|}
\hline Monomers & Product name & $\begin{array}{l}\text { Molecular } \\
\text { weight } \\
\text { [Da] }\end{array}$ & $\begin{array}{l}\text { Molecular } \\
\text { formula }\end{array}$ & Compound structure & $\begin{array}{l}\text { Retention } \\
\text { time } \\
{[\mathrm{min}]}\end{array}$ & $\begin{array}{l}\text { Found in chambe } \\
\text { experiment }\end{array}$ \\
\hline $\begin{array}{l}\text { Glutaric acid } \\
\gamma \text {-Butyrolactone }\end{array}$ & $\begin{array}{l}\text { Pentanedioic acid } \\
\text { mono-(3-carboxy- } \\
\text { propyl)ester }\end{array}$ & 218 & $\mathrm{C}_{9} \mathrm{H}_{14} \mathrm{O}_{6}$ & & 14.2 & $\begin{array}{l}\checkmark \\
\text { cyclohexene/O }\end{array}$ \\
\hline $\begin{array}{l}\text { Glutaric acid } \\
\delta \text {-Valerolactone }\end{array}$ & $\begin{array}{l}\text { Pentanedioic acid } \\
\text { mono-(4-carboxy- } \\
\text { butyl)ester }\end{array}$ & 232 & $\mathrm{C}_{10} \mathrm{H}_{16} \mathrm{O}_{6}$ & & 15.4 & $\begin{array}{l}\checkmark \\
\text { cyclohexene/O }\end{array}$ \\
\hline $\begin{array}{l}\text { Adipic acid } \\
\gamma \text {-Butyrolactone }\end{array}$ & $\begin{array}{l}\text { Hexanedioic acid } \\
\text { mono-(3-carboxy- } \\
\text { propyl)ester }\end{array}$ & 232 & $\mathrm{C}_{10} \mathrm{H}_{16} \mathrm{O}_{6}$ & & 15.3 & $\begin{array}{l}\checkmark \\
\text { cyclohexene/O }\end{array}$ \\
\hline $\begin{array}{l}\text { Succinic acid } \\
\varepsilon \text {-Caprolactone }\end{array}$ & $\begin{array}{l}\text { Butanedioic acid } \\
\text { mono-(5-carboxy- } \\
\text { pentyl)ester }\end{array}$ & 232 & $\mathrm{C}_{10} \mathrm{H}_{16} \mathrm{O}_{6}$ & & 1 & $x$ \\
\hline $\begin{array}{l}\text { Glutaric acid } \\
\varepsilon \text {-Caprolactone }\end{array}$ & $\begin{array}{l}\text { Pentanedioic acid } \\
\text { mono-(5-carboxy- } \\
\text { pentyl)ester }\end{array}$ & 246 & $\mathrm{C}_{11} \mathrm{H}_{18} \mathrm{O}_{6}$ & & 16.4 & $\begin{array}{l}\checkmark \\
\text { cyclohexene/O }\end{array}$ \\
\hline $\begin{array}{l}\text { Adipic acid } \\
\delta \text {-Valerolactone }\end{array}$ & $\begin{array}{l}\text { Hexanedioic acid } \\
\text { mono-(4-carboxy- } \\
\text { butyl)ester }\end{array}$ & 246 & $\mathrm{C}_{11} \mathrm{H}_{18} \mathrm{O}_{6}$ & & 16.2 & $\begin{array}{l}\checkmark \\
\text { cyclohexene/O }\end{array}$ \\
\hline $\begin{array}{l}\text { 2-Oxoglutaric } \\
\text { acid } \\
\delta \text {-Valerolactone }\end{array}$ & $\begin{array}{l}\text { 2-Oxopentanedioic } \\
\text { acid mono-(4- } \\
\text { carboxy-butyl)ester }\end{array}$ & 246 & $\mathrm{C}_{10} \mathrm{H}_{14} \mathrm{O}_{7}$ & & 1 & $x$ \\
\hline $\begin{array}{l}\text { Adipic acid } \\
\varepsilon \text {-Caprolactone }\end{array}$ & $\begin{array}{l}\text { Hexanedioic acid } \\
\text { mono-(5-carboxy- } \\
\text { pentyl)ester }\end{array}$ & 260 & $\mathrm{C}_{12} \mathrm{H}_{20} \mathrm{O}_{6}$ & & 17.1 & $\begin{array}{l}\checkmark \\
\text { cyclohexene/O }\end{array}$ \\
\hline $\begin{array}{l}\text { Pinic acid } \\
\delta \text {-Valerolactone }\end{array}$ & $\begin{array}{l}\text { Pinic acid mono-(4- } \\
\text { carboxy-butyl)ester }\end{array}$ & 286 & $\mathrm{C}_{14} \mathrm{H}_{22} \mathrm{O}_{6}$ & & 17.8 & $\begin{array}{l}\checkmark \\
\text { mix-experiment }\end{array}$ \\
\hline
\end{tabular}
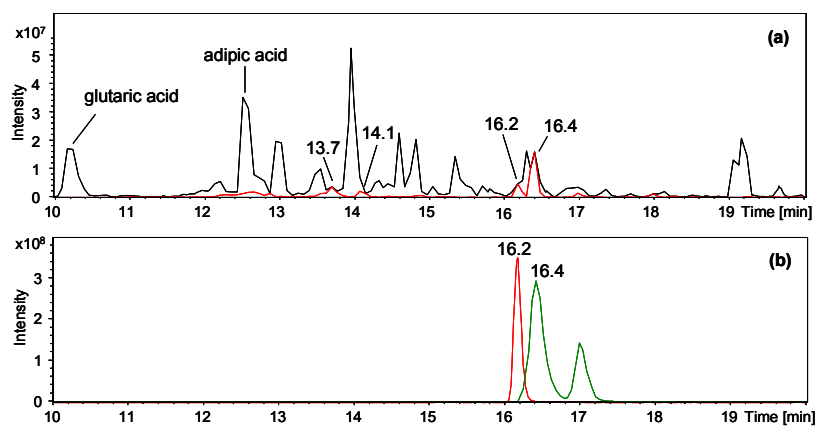

Fig. 4. HPLC-MS: Base-peak-chromatogram (black) and extractedion-chromatogram $\mathrm{m} / \mathrm{z}, 245$ of cyclohexene ozonolysis (red) (a) and extracted ion-chromatogram $\mathrm{m} / \mathrm{z}, 245$ of Pentanedioic acid mono(5-carboxy-pentyl)ester (green) and $\mathrm{m} / z, 245$ of Hexanedioic acid mono-(4-carboxy-butyl)ester (red) (b).

formed from $\alpha$-pinene ozonolysis prior addition of the cyclohexene. Beside the quasimolecular ions of well known products such as pinic $(\mathrm{m} / \mathrm{z}, 185)$, pinonic $(\mathrm{m} / \mathrm{z}, 183)$ or hydroxypinonic acid $(\mathrm{m} / \mathrm{z} 199)$, also several signals in the dimer region are clearly visible $(\mathrm{m} / \mathrm{z}$ values between about 280 and 380). After $100 \mathrm{~min}$ cyclohexene was added. The mass spectrum after cyclohexene addition is shown in Fig. 2c.

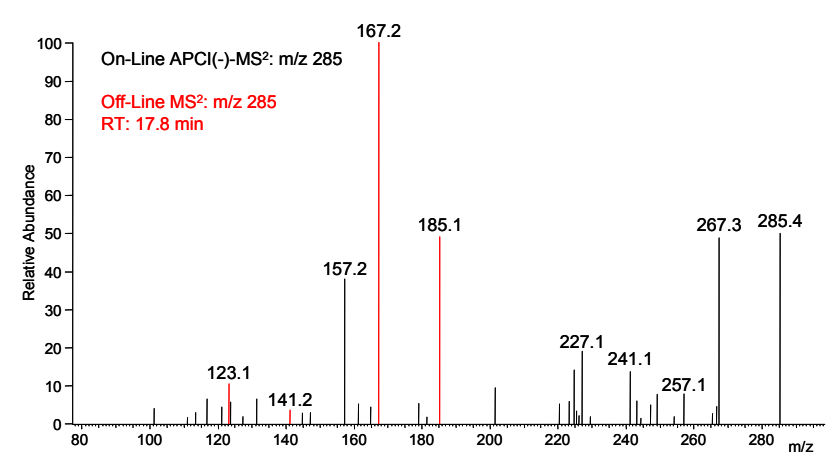

Fig. 5. On-Line $\mathrm{MS}^{2}$ of $\mathrm{m} / \mathrm{z}, 285$ from ozonolysis of cyclohexene and $\alpha$-pinene and common peaks (red) from off-line measurement.

As can be seen in the figure most of the monomeric products formed from the ozonolysis of the two individual precursors can still be observed. In contrast, the dimer region of the mass spectrum changed dramatically. Almost none of the dimers from the single compound experiments could be observed. However, two new signals emerged, $\mathrm{m} / \mathrm{z}$ 283 and $\mathrm{m} / \mathrm{z}$ 285. On-line MS/MS-experiments of $\mathrm{m} / \mathrm{z} 285$ pointed to a mixed dimer from $\alpha$-pinene and cyclohexene (see Fig. 5). Using the knowledge from the previous experiments, an ester compound was synthesized that should 

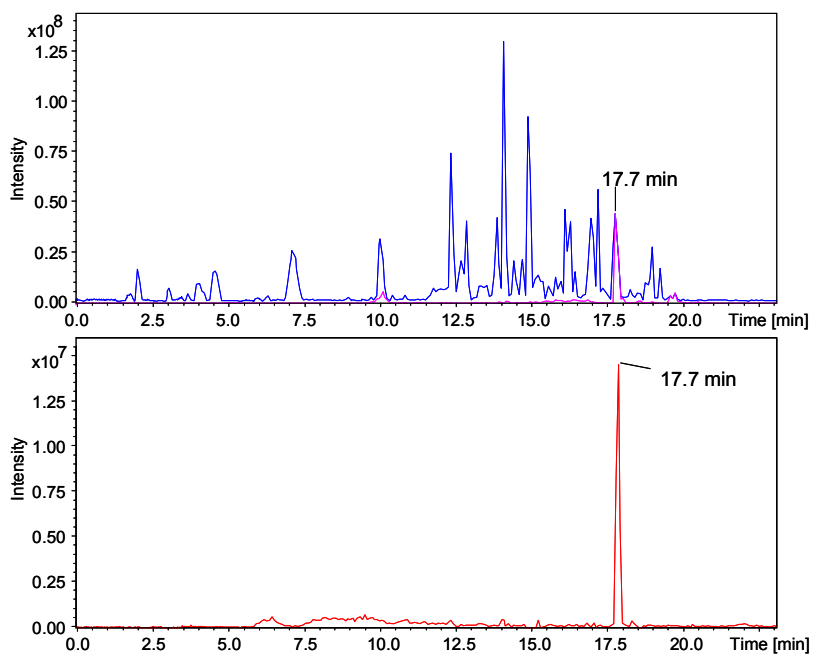

Fig. 6. HPLC-MS: Base-peak-chromatogram (blue) and extractedion-chromatogram $\mathrm{m} / \mathrm{z}, 285$ of cyclohexene/ $\alpha$-pinene ozonolysis (purple) (a) and extracted ion-chromatogram $\mathrm{m} / \mathrm{z} 285$ of Pinic acid mono-(4-carboxy-butyl)ester (b).
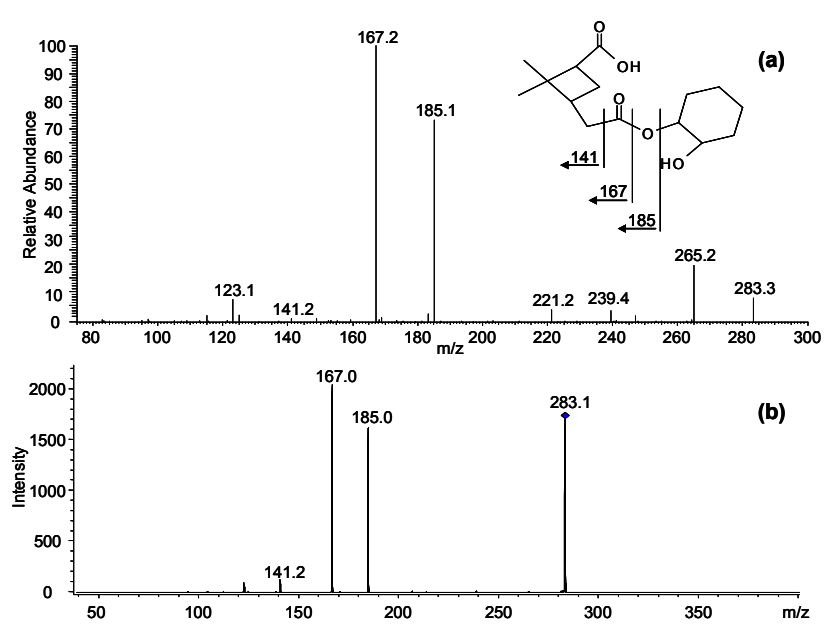

Fig. 7. On-Line (a) and off-line (b) $\mathrm{MS}^{2}$ of $\mathrm{m} / \mathrm{z}, 283$ from ozonolysis of cyclohexene and $\alpha$-pinene and possible structure $\&$ fragmentation pattern of the compound (a).

fit to the mass, the fragmentation pattern and the structure of the possible ester precursors formed during the $\alpha$-pinene and cyclohexene ozonolysis. The ester was synthesized from pinic acid and $\delta$-valerolactone (Table 1). The latter forms 6hydroxypentanoic acid if hydrolyzed. The resulting ester is pinic acid mono-(4-carboxy-butyl)ester. Filter samples and the synthesized product were characterized by LC/MS. The upper chromatogram in Fig. 6 shows the base-peak chromatogram of the filter sample (blue line) together with the extracted ion chromatogram of $\mathrm{m} / \mathrm{z}, 285$ (purple line). The lower chromatogram shows the extracted ion chromatogram

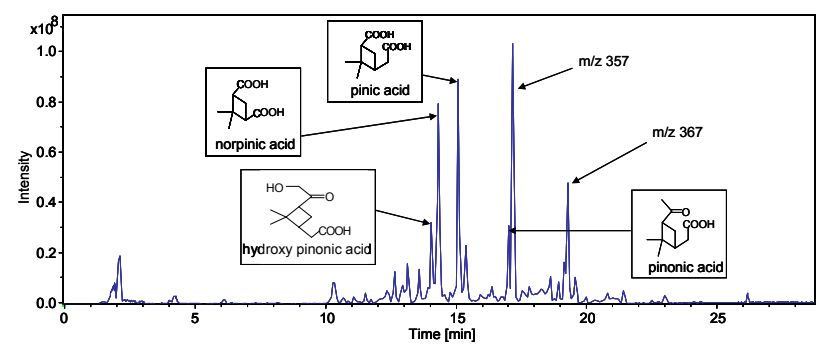

Fig. 8. HPLC-MS: Base peak chromatogram of $\alpha$-pinene oxidation products.

of $m / z 285$ of the synthesized reference compound (pinic acid mono-(4-carboxy-butyl)ester). Retention time and MS/MS spectra of the reference compound and the ozonolysis product of the cross experiment fit perfectly.

Due to the absence of reference compounds the newly formed $\mathrm{m} / \mathrm{z} 283$ in the mixed ozonolysis experiment can just be tentatively identified. The product could be an adduct of pinic acid and cyclohexene oxide. Figure 7 shows the on-line APCI(-)-MS ${ }^{2}$ (a) and the off-line ESI(-)-MS ${ }^{2}$ (b) spectra, as well as a possible structure of the formed compound. Both MS/MS spectra show the formation of the ions $\mathrm{m} / z$ 185, 167 and 141. These fragments could be explained as follows: $\mathrm{m} / \mathrm{z} 185$ is the quasi molecule ion of pinic acid; the other fragments are formed by dehydration $(\mathrm{m} / \mathrm{z}, 167)$ and decarboxylation $(\mathrm{m} / \mathrm{z}, 141)$ of pinic acid.

\section{$3.3 \alpha$-Pinene ozonolysis}

Building up on the information and conclusions from the experiments described above, it was also attempted to assign molecular structures to selected dimer products formed during a pure $\alpha$-pinene ozonolysis experiment. Several monomeric products observed in this system have already been mentioned above. In the dimer region (see Fig. 2b) the most abundant peaks in the on-line APCI-mass spectra were $\mathrm{m} / \mathrm{z} 337, \mathrm{~m} / \mathrm{z} 351$ and $\mathrm{m} / \mathrm{z} 367$ as well as a smaller but significant signal for $m / z$ 357. The LC/MS measurements of the appropriate samples show essentially the same masses, however, with different intensities. Here, $\mathrm{m} / \mathrm{z} 367$ and $\mathrm{m} / \mathrm{z}$ 357 are the most intensive signals in the higher molecular mass range (Fig. 8). MS/MS experiments were carried out to identify certain of these oligomers. Due to the reasons given above no reference compounds were accessible for an unambiguous identification. Consequently, the following suggestions are tentative. Based on the knowledge from cyclohexene ozonolysis and the cross-experiment it seems likely that the product $\mathrm{m} / \mathrm{z} 367$ again is a carboxylic acid ester, the ester formed between pinic acid and hydroxypinonic acid. The possible structure of this compound and off-line ESI(-)$\mathrm{MS}^{2}$ - and $\mathrm{MS}^{3}$-spectra are shown in Fig. 9a-c. Beside the signal of the dehydration product $(\mathrm{m} / \mathrm{z} 349)$, the acid component $(\mathrm{m} / z, 185$, pinic acid) of the ester is the most abundant 

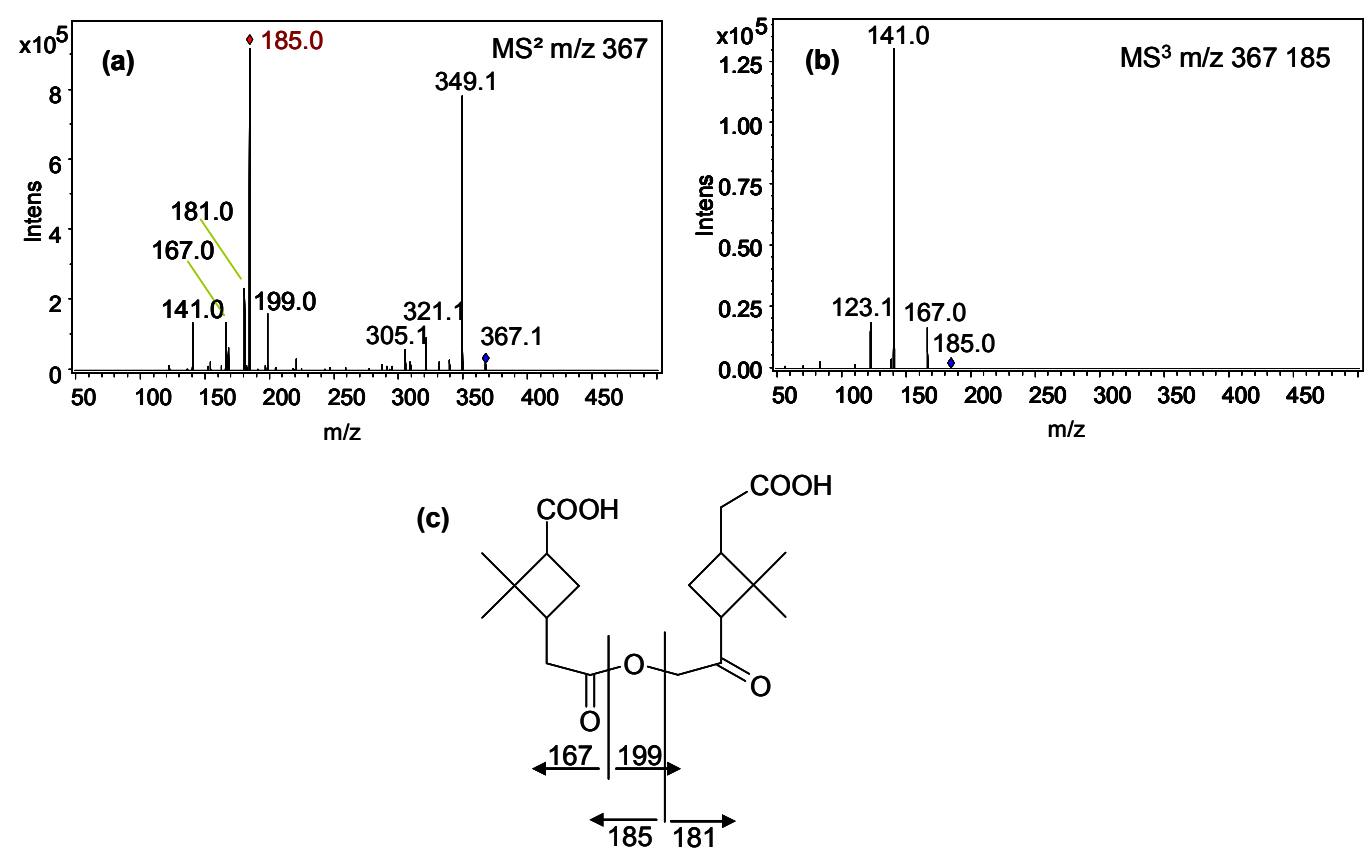

Fig. 9. LC-ESI-MS2 (a) and $-\mathrm{MS}^{3}$ spectra (b) of $\mathrm{m} / \mathrm{z}, 367$ from ozonolysis of cyclohexene and $\alpha$-pinene and possible structure of the compound (c).

fragment in the MS/MS spectrum of $m / z 367$ (Fig. 9a). In general, this fragmentation pattern was also observed for the reference esters investigated (see Fig. 3). However, also hydroxypinonic acid can be observed as a fragment ion by its quasimolecular ion $m / z$ 199. In the same spectrum also certain fragment ions, formed by the decomposition of pinic and hydroxypinonic acid ions are visible, e.g. dehydration $(\mathrm{m} / \mathrm{z}$ $167)$ and decarboxylation $(\mathrm{m} / \mathrm{z}, 141)$ of pinic acid and dehydration of hydroxypinonic acid $(\mathrm{m} / \mathrm{z}, 181)$. This fragmentation pattern is significant for dicarboxylic acids (Grossert et al., 2005) in general. The $\mathrm{MS}^{3}$-spectra of the daughter ion with $\mathrm{m} / z 185$ of $\mathrm{m} / \mathrm{z} 367$ (Fig. 9b) is practically identical to the $\mathrm{MS}^{2}$-spectra of pinic acid. The only significant difference between the MS/MS spectra of the ion with $m / z, 367$ and the reference esters (Fig. 3) is the loss of water (18 Da), which might be explained by the additional carbonyl group in the proposed ester structure.

\subsection{Possible reaction mechanisms}

One of the most interesting aspects of the ester formation is the question how these compounds are formed in SOA. Up to now, the reaction pathways leading to these esters are still unclear. One possibility would be the formation by the classical condensation reaction between an alcohol and an acid (esterification). Although this kind of ester formation was described to be thermodynamically favoured (Barsanti and Pankow, 2006), several aspects point against such a condensation reaction in the particle phase to explain the esters formed from cycloalkene ozonolysis. At first, we observed no significant influence of relative humidity $(\mathrm{RH})$ on the formation of esters in our studies. Since water is a product of the condensation reaction one could expect that lower RH should promote ester formation, although for a quantitative discussion of such an influence more information would be needed, e.g. about the concentration of particle phase water and equilibrium constants. Furthermore, the influence of relative humidity was not studied in detail here. However, investigations in a $\mathrm{RH}$ range between about $1 \%$ and $50 \%$ showed no significant change in the resulting mass spectra or product distribution. Obviously, these observations cannot rule out the possibility of condensation reactions leading to the ester, they just don't immediately support such a mechanism. Secondly, the ozonolysis of alkenes does not result in a high amount of hydroxyl carboxylic acids, which actually represent the alcohol component for all identified esters. One exception is 10-hydroxypinonic acid in case of $\alpha$-pinene (Glasius et al., 1999; Yu et al., 1999). Another argument against classical esterification reaction is the temporal behaviour of the concentrations of the "ester educts", e.g. pinic acids $(\mathrm{m} / \mathrm{z}, 185)$ and hydroxypinonic acid $(\mathrm{m} / \mathrm{z} 199)$, and the expected ester product $(\mathrm{m} / \mathrm{z}, 367)$ shown in Fig. 10. The fact that the product concentration $(\mathrm{m} / \mathrm{z} 367)$ increases faster than the concentration of the potential educts again does not directly suggest a second order reaction between the acid and the alcohol in the particle phase, although very fast consecutive reactions of the acids forming the ester or the lower volatility of the high molecular weight compound 


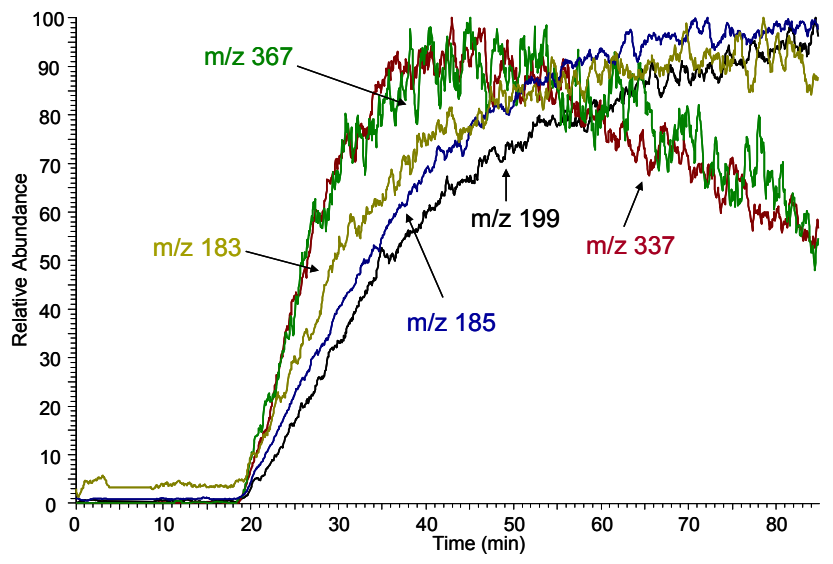

Fig. 10. On-line APCI-MS (neg. ion mode) of particulate products from the ozonolysis of $\alpha$-pinene. Ozone is added at $13 \mathrm{~min}$. Intensities of monomeric compounds like pinic acid $(\mathrm{m} / \mathrm{z}, 185)$, hydroxypinonic acid $(\mathrm{m} / \mathrm{z}, 199)$ and pinonic acid $(\mathrm{m} / \mathrm{z}, 183)$ rise slower than intensities of dimer compounds like $\mathrm{m} / z 337$ and $\mathrm{m} / \mathrm{z} 367$.

could also be made responsible for such behaviour. On the other hand, results from Joutsensaari et al. (2004) show that particulate organic acids can undergo auto-protonation catalyzed esterification within the timescale of a tandem-DMA experiment (seconds), although of course the reaction conditions were quite different (saturated alcohol atmosphere). Beside esterification reactions there exist other potential reaction pathways for ester formation. Docherty and coworkers suggest the decomposition of peroxyhemiacetals as formation pathway for esters in the particle phase (Docherty et al., 2005). Likewise, the decomposition of other potential peroxides formed in such reaction systems, such as diacyl peroxides (Ziemann, 2002), can also lead to ester formation (DeTar and Weis, 1957; Greene, 1955; Kharasch et al., 1954). Finally, other yet unidentified formation pathways might be involved, e.g. the direct ester formation by reactions of reactive intermediates in the gas or condensed phase. Clearly, more work is needed to clarify whether the esters observed here result from direct formation, from decomposition of unstable products or from heterogeneous reactions of alcohols and acids.

The formation the diacyl peroxide is believed to result from the recombination of acyl peroxy radicals in the gasphase (Ziemann, 2002). Ziemann suggests that these lowvolatility diacyl peroxides therefore might act as a nucleating agent in the atmosphere and that such products could play a role in new particle formation. Actually, the same would be true if the formation of the esters identified in this study would also occur via a gas phase mechanism, e.g. based on a similar reaction mechanism. At least the rapid formation of the esters in the reaction system, an observation that was already mentioned above, indicates the involvement of a very fast chemistry. Figure 11 shows that ester formation is at

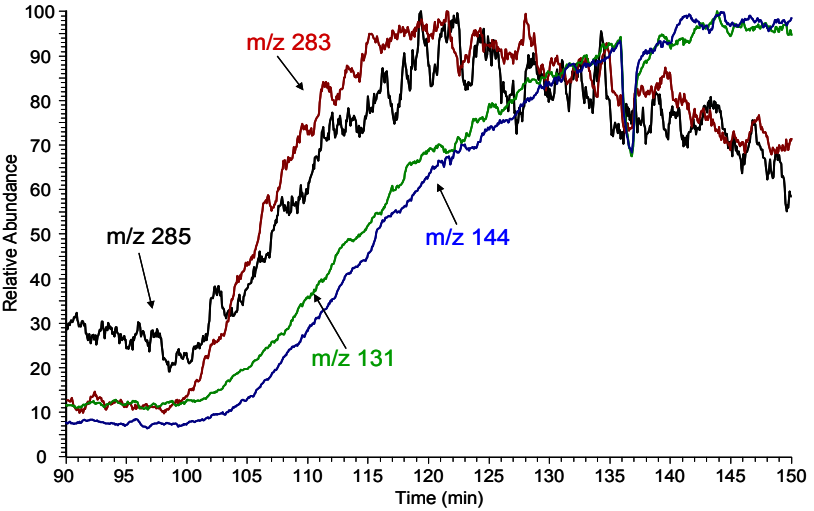

Fig. 11. On-line APCI-MS (neg. ion mode) of particulate products from the ozonolysis of $\alpha$-pinene and cyclohexene. Cyclohexene is added at $100 \mathrm{~min}$ to the running reaction of ozone and $\alpha$-pinene. Intensities of monomeric compounds from cyclohexene ozonolysis like glutaric acid $(\mathrm{m} / \mathrm{z}, 131)$ and adipic acid $(\mathrm{m} / \mathrm{z}, 145)$ rise slower than intensities of dimer compounds from the "cross reaction" of $\alpha$ pinene and cyclohexene constituents like ester compound $\mathrm{m} / \mathrm{z} 285$ and $m / z, 283$.

least as fast as the formation of other products during ozonolysis. Extracted ion chromatograms of ester compound $\mathrm{m} / \mathrm{z}$ 285 rises even faster than the monomeric products during the addition of cyclohexene to the running $\alpha$-pinene ozonolysis. Also the intensity of the $m / z$ value of dimeric products in the ozonolysis of pure $\alpha$-pinene rises faster than the intensity of monomeric products, such as pinic acid (Fig. 10). Therefore, the observed strong nucleation ability of terpenes, especially due to ozonolysis (Bonn and Moortgat, 2002) might also be connected to the formation of esters in the gas phase. However, as already mentioned above this potential influence on particle nucleation is only justified when the accretion reactions take place in the gas phase. When these reactions turn out to take place in the condensed phase, just the growth rate and the overall mass yield in organic aerosol formation would be affected.

\section{Conclusions}

A series of oxidation products in the higher molecular mass range from the cyclohexene/ozone reaction could clearly be identified as ester compounds. The identification was based on the comparison of mass spectra and retention times with synthesized reference compounds. Furthermore, ester formation was also verified in a cyclohexene $/ \alpha$-pinene $/ \mathrm{O}_{3}$ cross-experiment. Based on the information and conclusions from these experiments also certain dimeric products formed from an $\alpha$-pinene/ $\mathrm{O}_{3}$ reaction are suggested to be ester compounds. However, the reaction mechanism to the ester formation is not clear, although especially the temporal behaviour of the ester formation indicates that they are not 
formed by classical esterification reaction between alcohols and acids.

More simple esters (i.e. methyl-, ethylester) have been identified earlier in the ozonolysis of terpenes/cycloalkenes. For example, Gao and coworkers suggested carboxylic acid methyl- and ethylesters (Gao et al., 2004) and Yu and coworkers formic acid esters (Yu et al., 1999). Recently, esters were also found in SOA from isoprene (Surratt et al., 2006).

The analytical techniques used in this study also indicate that not all compounds in the dimer region of cycloalkene SOA can be explained by the formation of esters. Especially due to the differences in the MS/MS spectra between the identified esters and other oligomers observed in the reaction chamber as well as the fact that several compounds with the same $\mathrm{m} / \mathrm{z}$ ratio are formed simultaneously makes it likely that also other classes of dimeric products are formed. However, the chemical nature of these oligomers is not identified yet. Since for the incorporation of accretion reactions into atmospheric models the chemical mechanisms have to be understood, obviously the subject requires further investigations. Furthermore, although the results presented here are relevant to understand the results of reaction chamber experiments, also additional investigations need to be performed to evaluate the importance of these reactions under ambient conditions, e.g. by field measurements of appropriate dimeric target molecules.

Acknowledgements. This work was supported by the EC project POLYSOA (Polymers in Secondary Organic Aerosols).

Edited by: W. E. Asher

\section{References}

Alves, C., Pio, C., and Duarte, A.: The organic composition of air particulate matter from rural and urban Portuguese areas, Phys. Chem. Earth B, 24, 705-709, 1999.

Anttila, P., Hyotylainen, T., Heikkila, A., Jussila, M., Finell, J., Kulmala, M., and Riekkola, M. L.: Determination of organic acids in aerosol particles from a coniferous forest by liquid chromatography-mass spectrometry, J. Sep. Sci., 28, 337-346, 2005.

Barsanti, K. C. and Pankow, J. F.: Thermodynamics of the formation of atmospheric organic particulate matter by accretion reactions - Part 3: Carboxylic and dicarboxylic acids, Atmos. Environ., 40, 6676-6686, 2006.

Baumann, M. G. D., Batterman, S. A., and Zhang, G. Z.: Terpene emissions from particleboard and medium-density fiberboard products, Forest Prod. J., 49, 49-56, 1999.

Bonn, B. and Moortgat, G. K.: New particle formation during alpha- and beta-pinene oxidation by $\mathrm{O}_{3}, \mathrm{OH}$ and $\mathrm{NO}_{3}$, and the influence of water vapour: particle size distribution studies, Atmos. Chem. Phys., 2, 183-196, 2002,

http://www.atmos-chem-phys.net/2/183/2002/.
Bowman, F. M., Odum, J. R., Seinfeld, J. H., and Pandis, S. N.: Mathematical model for gas-particle partitioning of secondary organic aerosol, Atmos. Environ., 31, 3921-3931, 1997.

Claeys, M., Graham, B., Vas, G., Wang, W., Vermeylen, R., Pashynska, V., Cafmeyer, J., Guyon, P., Andreae, M. O., Artaxo, P., and Maenhaut, W.: Formation of secondary organic aerosols through photooxidation of isoprene, Science, 303, 1173-1176, 2004.

DeTar, D. F. and Weis, C.: Diacyl peroxide reactions III. The behaviour of optically active 3-Phenyl-2-propyl free radical, J. Am. Chem. Soc., 79, 3045-3049, 1957.

Docherty, K. S., Wu, W., Lim, Y. B., and Ziemann, P. J.: Contributions of organic peroxides to secondary aerosol formed from reactions of monoterpenes with $\mathrm{O}_{3}$, Environ. Sci. Technol., 39, 4049-4059, 2005.

Finlayson-Pitts, B. J. and Pitts, J. N. J.: Chemistry of the Upper and Lower Atmosphere, Academic Press, San Diego, 969 pp., 2000.

Gao, S., Keywood, M., Ng, N. L., Surratt, J., Varutbangkul, V., Bahreini, R., Flagan, R. C., and Seinfeld, J. H.: Low-molecularweight and oligomeric components in secondary organic aerosol from the ozonolysis of cycloalkenes and alpha-pinene, J. Phys. Chem. A, 108, 10 147-10 164, 2004.

Glasius, M., Duane, M., and Larsen, B. R.: Determination of polar terpene oxidation products in aerosols by liquid chromatography-ion trap mass spectrometry, J. Chromatogr. A, 833, 121-135, 1999.

Glasius, M., Lahaniati, M., Calogirou, A., Di Bella, D., Jensen, N. R., Hjorth, J., Kotzias, D., and Larsen, B. R.: Carboxylic acids in secondary aerosols from oxidation of cyclic monoterpenes by ozone, Environ. Sci. Technol., 34, 1001-1010, 2000.

Greene, F. D.: Reaction of Hydratropoyl Chloride with Sodium Peroxide, J. Am. Chem. Soc., 77, 4869-4873, 1955.

Grossert, J. S., Fancy, P. D., and White, R. L.: Fragmentation pathways of negative ions produced by electrospray ionization of acyclic dicarboxylic acids and derivatives, Can. J. Chem., 83, 1878-1890, 2005.

Hamilton, J. F., Lewis, A. C., Reynolds, J. C., Carpenter, L. J., and Lubben, A.: Investigating the composition of organic aerosol resulting from cyclohexene ozonolysis: low molecular weight and heterogeneous reaction products, Atmos. Chem. Phys., 6, 4973 4984, 2006, http://www.atmos-chem-phys.net/6/4973/2006/.

Hinds, W. C.: Aerosol Technology, John Wiley \& Sons, Inc., New York, 438 pp., 1999.

Hodgson, A. T., Beal, D., and Mcllvaine, J. E. R.: Sources of formaldehyde, other aldehydes and terpenes in a new manufactured house, Indoor Air, 12, 235-242, 2002.

Hoffmann, T., Bandur, R., Marggraf, U., and Linscheid, M.: Molecular composition of organic aerosols formed in the alphapinene $/ \mathrm{O}_{3}$ reaction: Implications for new particle formation processes, J. Geophys. Res., 103, 25 569-25 578, 1998.

Hoffmann, T., Bandur, R., and Seinfeld, J. H.: Experimental and theoretical studies on the aerosol formation potential of natural VOCs, Proceedings of the Workshop on Biogenic Hydrocarbons in the Atmospheric Boundary Layer, Amer. Meteor. Soc., August 24-27, 1997, University of Virginia, Charlottesville, Virginia, 131-134, 1997.

Holmes, N. S.: A review of particle formation events and growth in the atmosphere in the various environments and discussion of mechanistic implications, Atmos. Environ., 41, 2183-2201, 
2007.

Iinuma, Y., Böge, O., Gnauk, T., and Herrmann, H.: Aerosolchamber study of the a-pinene/O3 reaction: influence of particle acidityon aerosol yields and products, Atmos. Environ., 38, 761-773, 2004.

Joutsensaari, J., Toivonen, T., Vaattovaara, P., Vesterinen, M., Vepsalainen, J., and Laaksonen, A.: Time-resolved growth behavior of acid aerosols in ethanol vapor with a tandem-DMA technique, J. Aerosol Sci., 35, 851-867, 2004.

Kalberer, M., Paulsen, D., Sax, M., Steinbacher, M., Dommen, J., Prevot, A. S. H., Fisseha, R., Weingartner, E., Frankevich, V., Zenobi, R., and Baltensperger, U.: Identification of polymers as major components of atmospheric organic aerosols, Science, 303, 1659-1662, 2004.

Kalberer, M., Yu, J., Cocker, D. R., Flagan, R. C., and Seinfeld, J. H.: Aerosol formation in the cyclohexene-ozone system, Environ. Sci. Technol., 34, 4894-4901, 2000.

Kavouras, I. G., Mihalopoulos, N., and Stephanou, E. G.: Formation and gas/particle partitioning of monoterpenes photo- oxidation products over forests, Geophys. Res. Lett., 26, 55-58, 1999.

Kharasch, M. S., Kuderna, J., and Nudenberg, W.: Formation of optically active esters in the decomposition of optically active diacyl peroxides in solution, J. Org. Chem., 19, 1283-1289, 1954.

Koch, S., Winterhalter, R., Uherek, E., Kolloff, A., Neeb, P., and Moortgat, G. K.: Formation of new particles in the gas-phase ozonolysis of monoterpenes, Atmos. Environ., 34, 4031-4042, 2000.

Lack, D. A., Tie, X. X., Bofinger, N. D., Wiegand, A. N., and Madronich, S.: Seasonal variability of secondary organic aerosol: A global modeling study, J. Geophys. Res., 109, D03203, doi:10.1029/2003JD003418, 2004.

Larsen, B. R., Di Bella, D., Glasius, M., Winterhalter, R., Jensen, N. R., and Hjorth, J.: Gas-phase $\mathrm{OH}$ oxidation of monoterpenes: Gaseous and particulate products, J. Atmos. Chem., 38, 231-276, 2001.

Odum, J. R., Hoffmann, T., Bowman, F., Collins, D., Flagan, R. C., and Seinfeld, J. H.: Gas/particle partitioning and secondary organic aerosol yields, Environ. Sci. Technol., 30, 2580-2585, 1996.
Sarwar, G., Olson, D. A., Corsi, R. L., and Weschler, C. J.: Indoor fine particles: The role of terpene emissions from consumer products, J. Air Waste Manage. Assoc., 54, 367-377, 2004.

Seinfeld, J. H. and Pandis, S. N.: Atmospheric chemistry and physics, John Wiley \& Sons Inc., New York, 1326 pp., 1998.

Surratt, J. D., Murphy, S. M., Kroll, J. H., Ng, N. L., Hildebrandt, L., Sorooshian, A., Szmigielski, R., Vermeylen, R., Maenhaut, W., Claeys, M., Flagan, R. C., and Seinfeld, J. H.: Chemical composition of secondary organic aerosol formed from the photooxidation of isoprene, J. Phys. Chem. A, 110, 9665-9690, 2006.

Tobias, H. J. and Ziemann, P. J.: Thermal desorption mass spectrometric analysis of organic aerosol formed from reactions of 1-tetradecene and $\mathrm{O}_{3}$ in the presence of alcohols and carboxylic acids, Environ. Sci. Technol., 34, 2105-2115, 2000.

Tolocka, M. P., Jang, M., Ginter, J. M., Cox, F. J., Kamens, R. M., and Johnston, M. V.: Formation of oligomers in secondary organic aerosol, Environ. Sci. Technol., 38, 1428-1434, 2004.

Tsigaridis, K. and Kanakidou, M.: Global modelling of secondary organic aerosol in the troposphere: a sensitivity analysis, Atmos. Chem. Phys., 3, 1849-1869, 2003, http://www.atmos-chem-phys.net/3/1849/2003/.

Warnke, J., Bandur, R., and Hoffmann, T.: Capillary-HPLC-ESIMS/MS method for the determination of acidic products from the oxidation of monoterpenes in atmospheric aerosol samples, Anal. Bioanal. Chem., 385, 34-45, 2006.

Yu, J. Z., Cocker, D. R., Griffin, R. J., Flagan, R. C., and Seinfeld, J. H.: Gas-phase ozone oxidation of monoterpenes: Gaseous and particulate products, J. Atmos. Chem., 34, 207-258, 1999.

Ziemann, P.: Evidence for low-volatility diacyl peroxides as a nucleating agent and major component of aerosol formed from reactions of $\mathrm{O}_{3}$ with cyclohexene and homologous compounds, J. Phys. Chem. A, 106, 4390-4402, 2002.

Ziemann, P. J.: Formation of alkoxyhydroperoxy aldehydes and cyclic peroxyhemiacetals from reactions of cyclic alkenes with $\mathrm{O}_{3}$ in the presence of alcohols, J. Phys. Chem. A, 107, 20482060, 2003. 